\title{
THERMAL ANALYSIS ON THE SHIPMENT OF RUSSIAN PLUTONIUM FUEL
}

\author{
Chuen T. Or, Emanuel A. Skrabek, and Robert T. Carpenter \\ Orbital Sciences Corporation \\ 20301 Century Blvd. \\ Germantown, MD 20874 \\ (301) 428-1168
}

Twelfth Symposium

on Space Nuclear Power and Propulsion

Albuquerque, New Mexico

January 1995 


\title{
THERMAL ANALYSIS ON THE SHIPMENT OF RUSSIAN PLUTONIUM FUEL
}

\author{
Chuen T. Or, Emanuel A. Skrabek, and Robert T. Carpenter \\ Orbital Sciences Corporation \\ 20301 Century Blvd. \\ Germantown, MD 20874 \\ (301) 428-1168
}

Twelfth Symposium

on Space Nuclear Power and Propulsion

Albuquerque, New Mexico

January 1995 


\title{
THERMAL ANALYSIS ON THE SHIPMENT OF RUSSIAN PLUTONIUM FUEL
}

\author{
Chuen T. Or, Emanuel A. Skrabek, and Robert T. Carpenter \\ Orbital Sciences Corporation \\ 20301 Century Blvd. \\ Germantown, MD 20874
}

(301) 428-1168

\begin{abstract}
The Mound 9516 Shipping Package was designed for the shipment of plutonium-238 fuel. One of the shipping configurations is the Russian Pu-238 Powder Can. Computer models using SINDA were created to predict the temperatures of the Package under Normal Conditions of Transport (NCT: $311 \mathrm{~K}$ ambient temperature), under Hypothetical Accident Conditions (HAC: engulfed in $1075 \mathrm{~K}$ fire for 30 minutes), and inside a standard cargo container. Pressure increases inside the Package due to the expansion of the trapped gases and helium gas generation from isotope decay were also analyzed.
\end{abstract}

\section{BACKGROUND}

The Mound 9516 Shipping Package was originally called Mound One Kilowatt Package. It was designed for the shipment of plutonium (Pu-238) with not more than $1 \mathrm{~kW}$ total heat dissipation. The design specifications on temperatures for the containment vessels were $811 \mathrm{~K}$ $\left(538^{\circ} \mathrm{C}\right)$ under Normal Conditions of Transport (NCT) and $1089 \mathrm{~K}\left(816^{\circ} \mathrm{C}\right)$ under Hypothetical Accident Conditions (HAC) (Coleman 1991 and Or 1994). The authors created some simple and very conservative computer models to show that all the shipping configurations (8-GIS, 16-clad, 3-GPHS, 9-MHW) meet the design specifications (Or 1994).

The maximum temperature limit under NCT was subsequently lowered from $811 \mathrm{~K}\left(538^{\circ} \mathrm{C}\right)$ to $700 \mathrm{~K}\left(427^{\circ} \mathrm{C}\right)$ We refined the models to demonstrate that the Package also met the new specifications. However, the reviewers insisted that all the conservative assumptions in the original models had to be retained. With the tightened specifications and high degree of conservatism required, the only option left was to reduce the fuel loading in each package.

\section{PHYSICAL INFORMATION OF MOUND 9516 SHIPPING PACKAGE}

The Mound 9516 Shipping Package consists of a stainless steel frame and wire mesh personnel shield (cage) that completely encloses a stainless steel cask. Figure 1 shows the assembled package. Inside the cask is the welded leaktight Secondary Containment Vessel (SCV). Inside the SCV are the welded leaktight Primary Containment Vessels (PCVs). Figure 2 shows the confinement boundary of the package and the two levels of containment. 


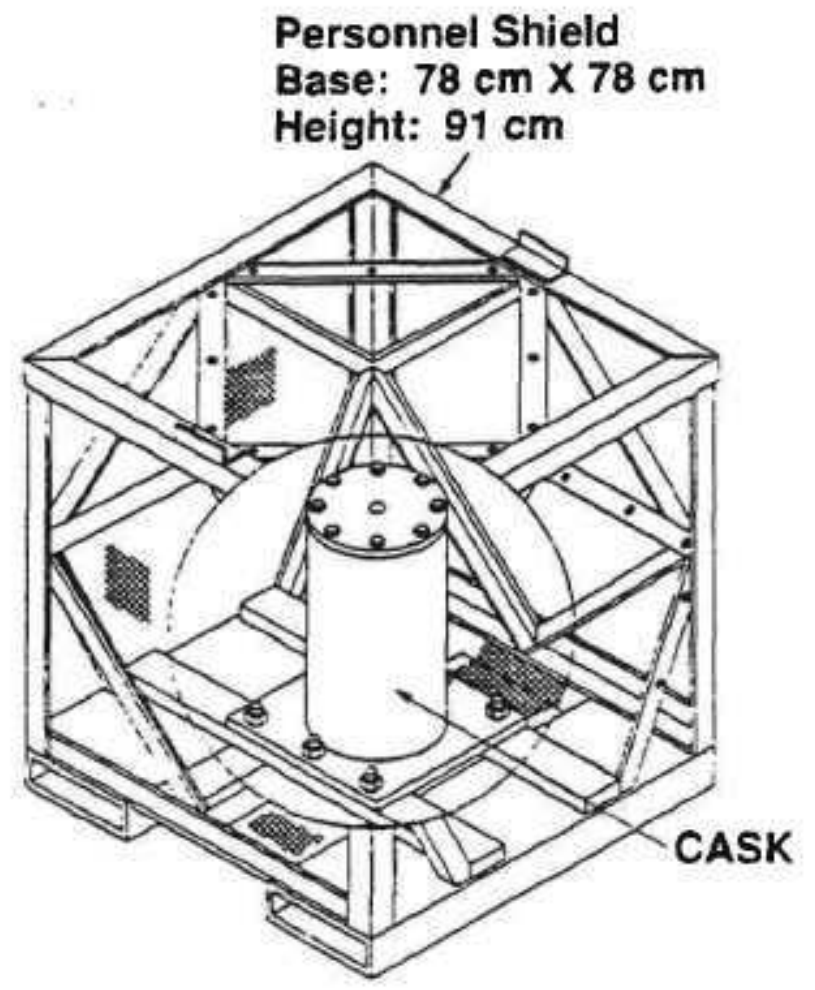

FIGURE 1. Mound 9516 Shipping Package (Excerpt from Coleman 1991).

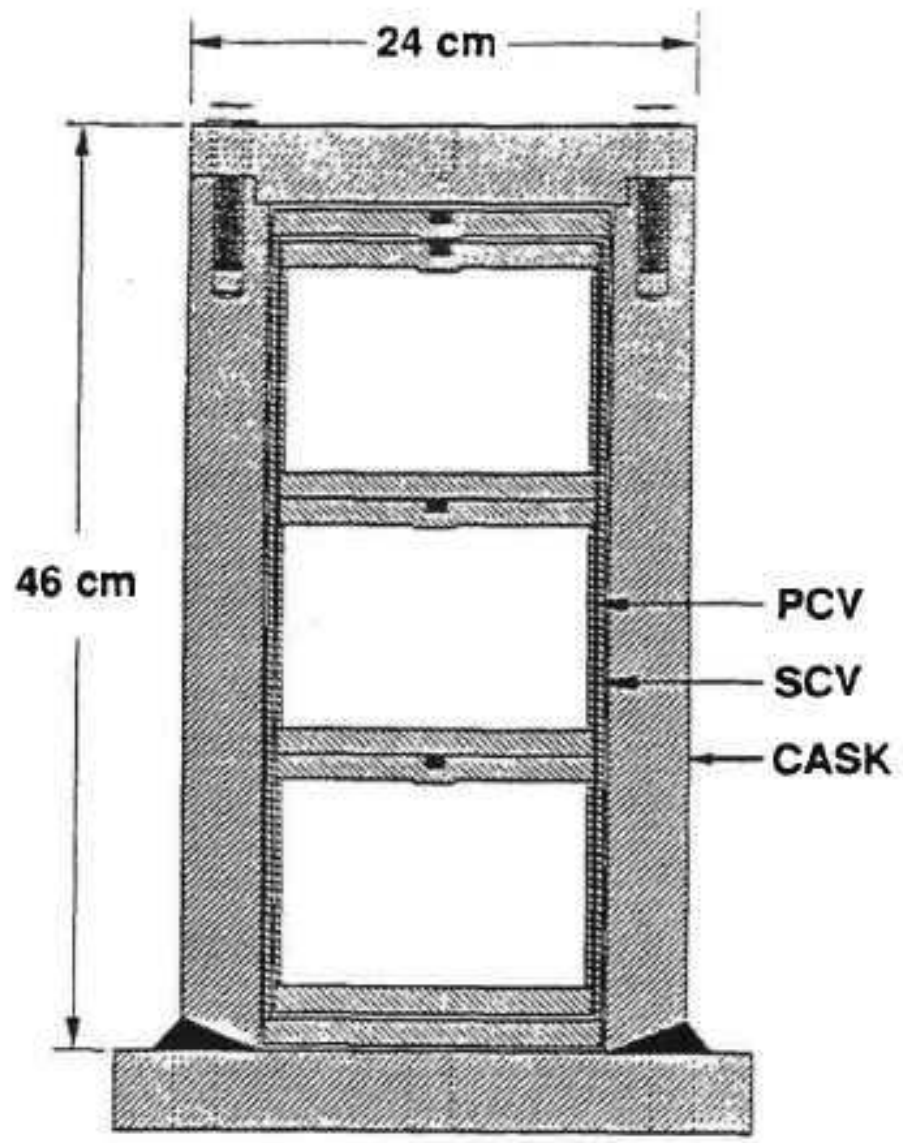

FIGURE 2. Cut-away View of Cask and Containment Vessels (Excerpt from Coleman 1991).

\section{THERMAL MODELS}

A finite difference computer code called SINDA (System Improved Numerical Differencing Analyzer) (Gaski 1986) was used to perform the thermal analyses. Where necessary, SSPTA (Simplified Space Payload Thermal Analyzer) (Little 1986) was used to calculate the radiation exchange between surfaces.

In the NCT, regulations require that the containment vessels can be sealed for up to one year, and that the package must be capable of withstanding exposure to an ambient temperature of $311 \mathrm{~K}$ in still air with solar insolation without substantial reduction in the effectiveness of the package. In the HAC, regulations require the package to go through a 9 meter drop before the fire. In previous testing and analysis (Coleman 1991), the cage was severely damaged after the drop test. The cask was not damaged but was thermally decoupled from the cage. Therefore, only the cask is required to go through the fire tests.

A 3-D model of only the bare cask was used to predict temperatures in both NCT and HAC. Cooling by the cage was not credited in the steady state analyses of the NCT and in setting the 
initial temperature of the HAC analyses. Modeling assumptions and material properties used can be found in "Evaluation of the Mound 1 kW Package, Russian Product Can Configuration," (H\&R 1993).

From the cask outer surface, both radiation and convection heat transfer are included in the models in both NCT and HAC calculations. Constant wall temperature was assumed for convection to and from the cask wall. For laminar flow on a vertical wall (Kays 1980)

$$
\mathrm{Nu}_{(\mathrm{x})}=3 / 4\left[2 \mathrm{Pr} / 5\left(1+2 \mathrm{Pr}^{1 / 2}+2 \mathrm{Pr}\right)\right]^{1 / 4}\left[\mathrm{Gr}_{(\mathrm{x})} \operatorname{Pr}\right]^{1 / 4},
$$

where Nu, Pr, Gr are the Nusselt, Prandtl, and Grasshoff numbers respectively. In this equation they are all local properties. The equation leads to

$$
H(x) \propto x^{-1 / 4}
$$

The convective heat transfer coefficient $\mathrm{H}$ is a weak function of the axial distance $\mathrm{x}$. Therefore, for simplicity in modeling, the average heat transfer coefficient was used for the cask wall. Integrating along the wall, the average Nusselt number $\mathrm{Nu}$ is

$$
\mathrm{Nu}=\left[2 \mathrm{Pr} / 5\left(1+2 \mathrm{Pr}^{1 / 2}+2 \mathrm{Pr}\right)\right]^{1 / 4}[\mathrm{Gr} \cdot \mathrm{Pr}]^{1 / 4} . \quad \mathrm{Gr}<10^{9}
$$

For the convective heat transfer for cask top and cask baseplate, (Gebhart 1971):

1. For horizontal surface facing upward

$$
\begin{array}{ll}
\mathrm{Nu}=0.54(\mathrm{Gr} \cdot \mathrm{Pr})^{1 / 4}, & 10^{5}<\mathrm{Gr} \bullet \operatorname{Pr}<10^{7} \\
\mathrm{Nu}=0.14(\mathrm{Gr} \cdot \mathrm{Pr})^{1 / 3} . & 10^{7}<\mathrm{Gr} \cdot \operatorname{Pr}<3 \times 10^{10}
\end{array}
$$

2. For horizontal surfaces facing downward

$$
\mathrm{Nu}=0.27(\mathrm{Gr} \cdot \mathrm{Pr})^{1 / 4}, \quad 3 \times 10^{5}<\mathrm{Gr} \cdot \mathrm{Pr}_{\mathrm{r}}<3 \times 10^{10}
$$

where the length scale $=$ surface area/perimeter. (Results from thermal analyses were checked to confirm that the Grasshof numbers were within ranges specified.)

Inside the cask, only radiation and conduction heat transfer were included in the model. Convection through the small gaps is negligible compared with conduction. In the thermal model, the thermal conductivity of all solids and gases, and the kinematic viscosity and bulk modulus of air are varying with temperature. Consequently, the thermal conductances and the convective heat transfer coefficients are updated in every iteration.

In the transient analyses, the same models used for steady state analyses were used. Heat capacitance of all solids were added. Time varying environments were switched accordingly for 
the initial conditions, cask engulfed in fire, and cask after the fire. All the temperature dependent properties described above were updated in every output time step specified.

\section{Pressure Inside PCV Calculations}

Regulations require that the containment vessels can be sealed for up to one year before shipment. To ensure the structural integrity, it is necessary to calculate the pressure increase in the PCV resulting from thermal expansion of the cover gases and the helium generated from the alpha decay of Pu-328.

The mass of each gas component $\mathrm{M}_{\mathrm{j}}$ is the sum of the mass of that particular gas trapped in each void volume $V_{i}$ given by:

$$
M_{j}=\sum_{i} M_{j i}=\frac{1}{R_{j}} \sum_{i} \frac{P_{j i} V_{i}}{T_{i}}
$$

The partial pressure $P_{\mathrm{ji}}$ of gas component $\mathrm{j}$ in each void volume $\mathrm{V}_{\mathrm{i}}$ is the same as the partial pressure of that gas in the welding enclosure. $T_{i}$ is the absolute temperature of the gas in void volume $V_{i}$ at the moment the container is welded-shut. $R_{j}$ is the gas constant of gas $j$.

Helium is generated by the isotope decay of Pu-238. The decrease in Pu-238 mass $\Delta \mathrm{M}_{\mathrm{Pu}}$ is given by:

$$
\Delta \mathrm{M}_{\mathrm{Pu}}=\mathrm{M}_{\mathrm{o}}\left(1-\mathrm{e}^{-\lambda \mathrm{t}}\right) \text {, }
$$

where $\mathrm{M}_{\mathrm{O}}$ is the initial Pu-238 mass, $\lambda$ is $\ln 2 /$ half life of Pu-238 ( 87.74 years), and $t$ is the time of interest for the isotope decay. Each atom of Pu-238 decay produces one atom of helium. Therefore the mass of helium generation $\mathrm{M}_{\mathrm{G}}$ is:

$$
M_{G}=\frac{M_{\text {Hee }}}{M_{\text {Pu238 }}} M_{o}\left(1-e^{-\lambda_{1}}\right),
$$

where $\mathrm{M}_{\mathrm{He}}$ is the atomic mass of helium, $\mathrm{M}_{\mathrm{Pu} 238}$ is the atomic mass of Pu-238.

After one year of storage, the pressure increase on the PCV wall depends greatly on the amount of leakage of the Russian Product Cans, Capsules, and Ampoules. The pressure increase is highest if gases are free to move in and out of these containers. Under this worst case scenario the new partial pressure $\mathrm{Pj}_{\mathrm{j}}$ of any gas $\mathrm{j}$ is uniform everywhere inside the PCV and its value is given by:

$$
P_{j}=M_{j} R_{j} /\left(\sum_{i} \frac{V_{i}}{T_{2 i}}\right),
$$

where $T_{2 i}$ is the new gas temperature in void volume $V_{i} . \quad T_{2 i}$ is determined by steady state analysis under NCT. The total pressure on the PCV wall $\mathrm{P}_{\mathrm{PCV}}$ is the sum of the partial pressures from the trapped gases and from the helium generated from alpha decay $\mathrm{P}_{\mathrm{G}}$. 


$$
\begin{aligned}
P_{P C V} & =\sum_{j} P_{j}+P_{G} \\
& =\left(\sum_{j} M_{j} R_{j}+M_{G} R_{H e}\right) /\left(\sum_{i} \frac{V_{i}}{T_{2 i}}\right)
\end{aligned}
$$

where $\mathbf{R}_{\mathrm{He}}$ is the gas constant of helium.

\section{RESULTS AND DISCUSSION}

\section{NCT and HAC}

NCT analyses were performed by steady state analyses of the bare cask model in which solar insolation was applied; the cask was placed on an adiabatic surface radiating and convecting to a $311 \mathrm{~K}$ environment. Cooling by the cage was not credited. The predictions were conservative. Figure 3 shows the results of the steady state analysis under NCT.

In the NCT, the reviewers' interpretation of the regulations is that the PCV should not exceed $700 \mathrm{~K}$. As shown in Figure 3, the maximum PCV temperature of $653 \mathrm{~K}\left(380^{\circ} \mathrm{C}\right)$ is well within the $700 \mathrm{~K}$ limit.

In the HAC analyses, the initial temperatures were set by steady state analysis of the bare cask without taking credit of cooling by the cage. The cask was levitated in a room (no solar insolation), convecting to $311 \mathrm{~K}$ air and radiating to $311 \mathrm{~K}$ wall. Then the cask was levitated in a large furnace with $1075 \mathrm{~K}$ wall and $1075 \mathrm{~K}$ air for 30 minutes. To account for black soot covering the cask, the emissivity of cask outer surfaces was increased from 0.7 to 0.8 . Then the cask was moved back to the room for cooling. Figure 4 shows the temperature variation with time of each component at the hottest locations. As shown, the maximum temperature of the PCV of $831 \mathrm{~K}\left(558^{\circ} \mathrm{C}\right)$ and the SCV of $896 \mathrm{~K}\left(623^{\circ} \mathrm{C}\right)$ is much lower than the $1089 \mathrm{~K}$ plastic limit (Coleman 1991 and Or 1994). Therefore both PCVs and SCV do not fail in the fire.

\section{Inside a Standard Cargo Container}

There was a concern that when the shipping packages sit in an enclosed standard cargo container with recirculating air inside instead of free flowing air as in the NCT, the temperatures of the containment vessels might exceed the specifications. Again the bare cask model was used to predict the temperatures. In the analyses, the cask was levitated $0.25 \mathrm{~m}$ above the container bottom radiating to the container. The recirculating air also contributed in transferring heat from the cask to the container.

Results show that the maximum PCV temperature is substantially below the limit. The analysis was then expanded to placing 3 shipping packages in the container. The temperatures of the middle cask are shown in Figure 5. As can be seen, the maximum PCV temperature of $656 \mathrm{~K}$ $\left(383^{\circ} \mathrm{C}\right)$ from this conservative analysis is well within the $700 \mathrm{~K}$ limit. 


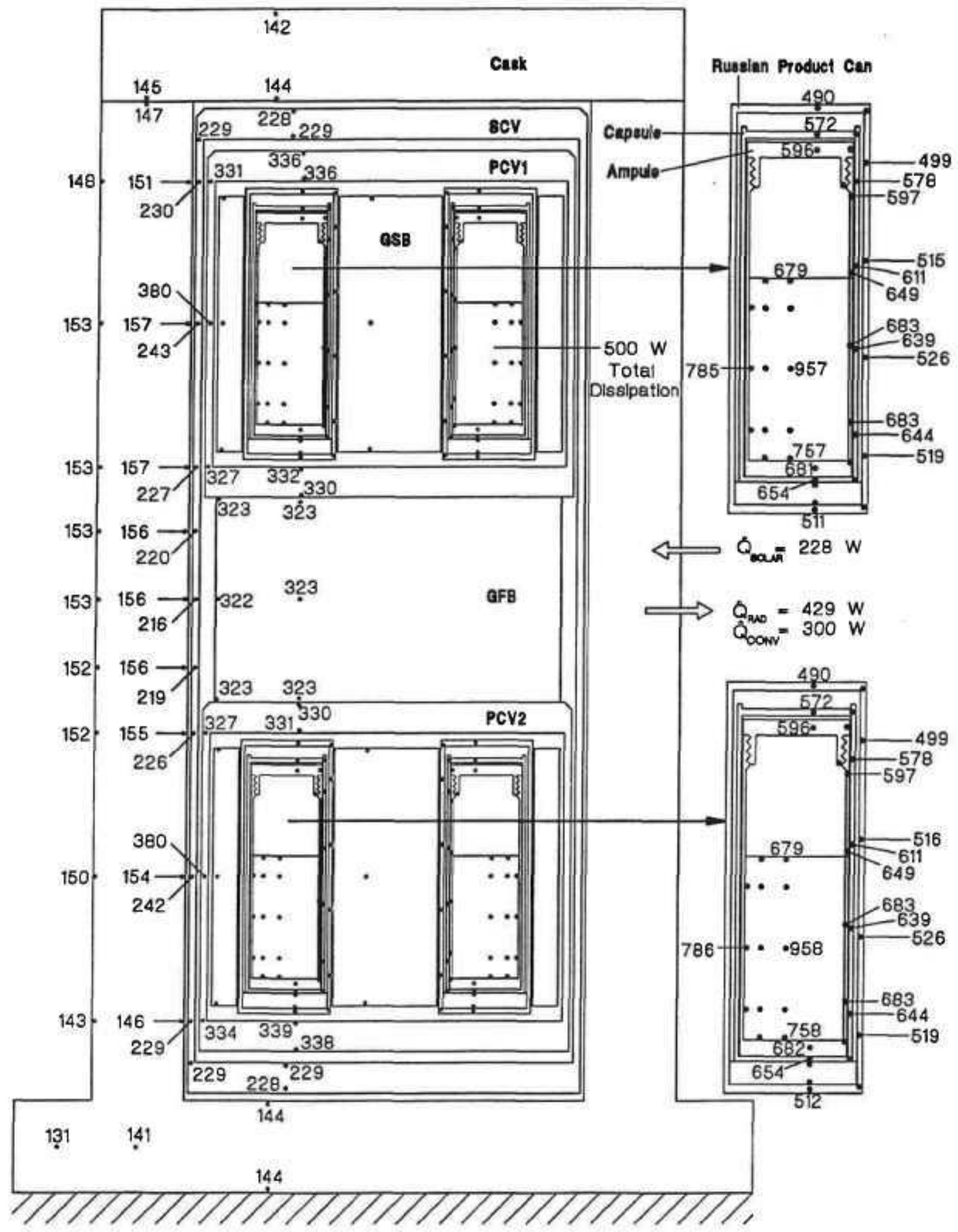

FIGURE 3. Steady State Temperatures in Normal Conditions of Transport. 


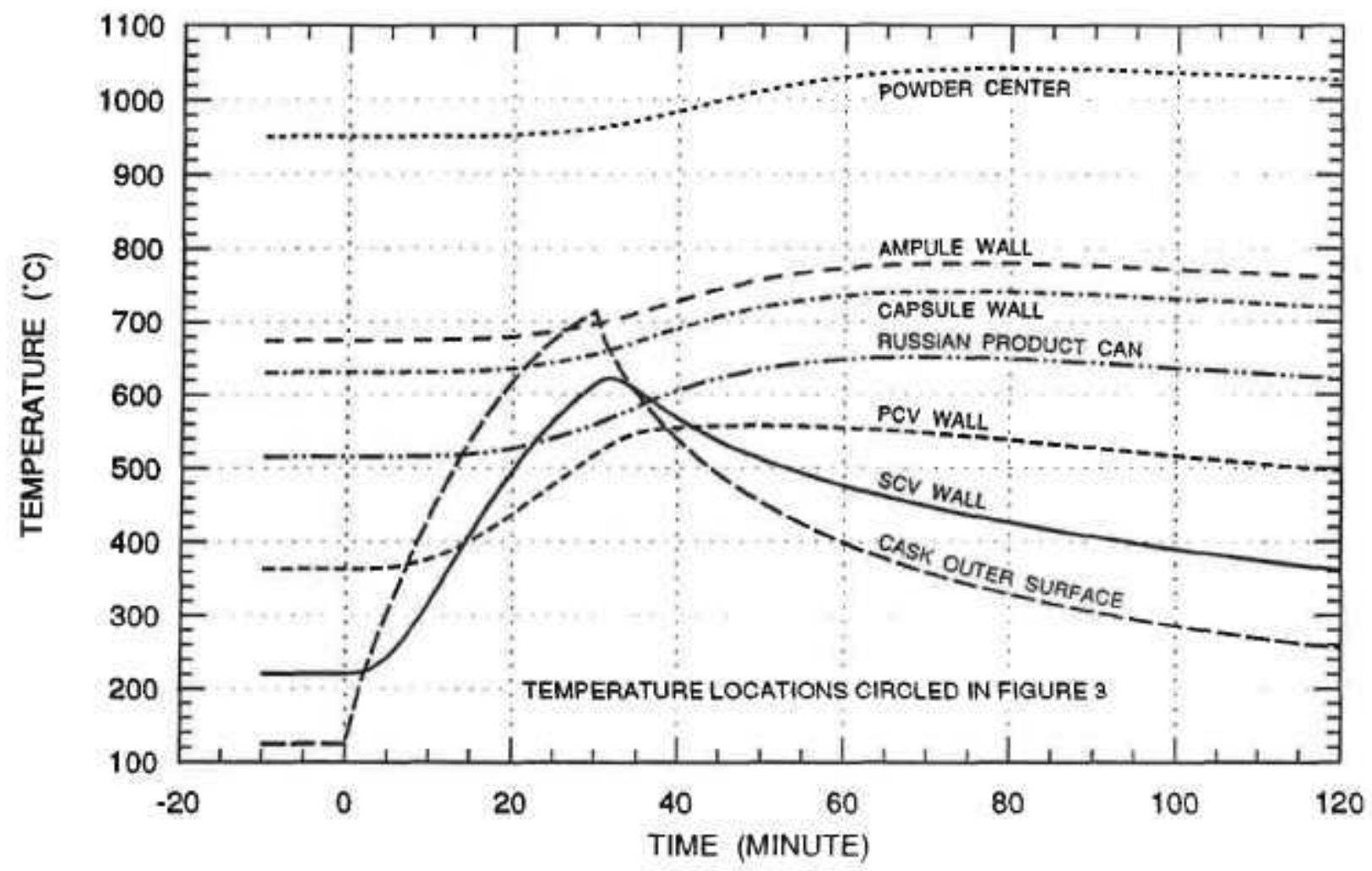

FIGURE 4. Transient Temperatures in Hypothetical Accident Conditions.

\section{Pressure inside PCV}

To calculate the maximum possible pressure on the PCV: the maximum mass of trapped gases was calculated; the maximum mass of helium generated by alpha decay was calculated; the gases were assumed to be free to move in and out of the powder containers; and the maximum steady state temperatures were used to calculate the gas pressures.

Ambient temperature of $293 \mathrm{~K}$ and one atmosphere pressure were used to calculate the amount of trapped gases. In reality, the gases are much hotter because of the heat from welding and from isotope decay. Also, the weld chamber pressure is lower than one atmosphere to ensure in-leakage. 500 watts of thermal loading and one year's time were used to calculate the total mass of helium generated.

To calculate the final gas temperatures in the voids, temperatures predicted from NCT shown in Figure 3 were used. For simplicity, the maximum wall temperature surrounding the void instead of the average wall temperature was used.

Conservative assumptions were used every step along the way. The maximum internal pressure on the $\mathrm{PCV}$ was calculated to be $335 \mathrm{kPa}$ ( $48.6 \mathrm{psia}$ ) and is substantially below the 749 $\mathrm{kPa}$ (108.6 psia) limit, (Table 2.7 in SARP, Rev. 3, Coleman 1992). 


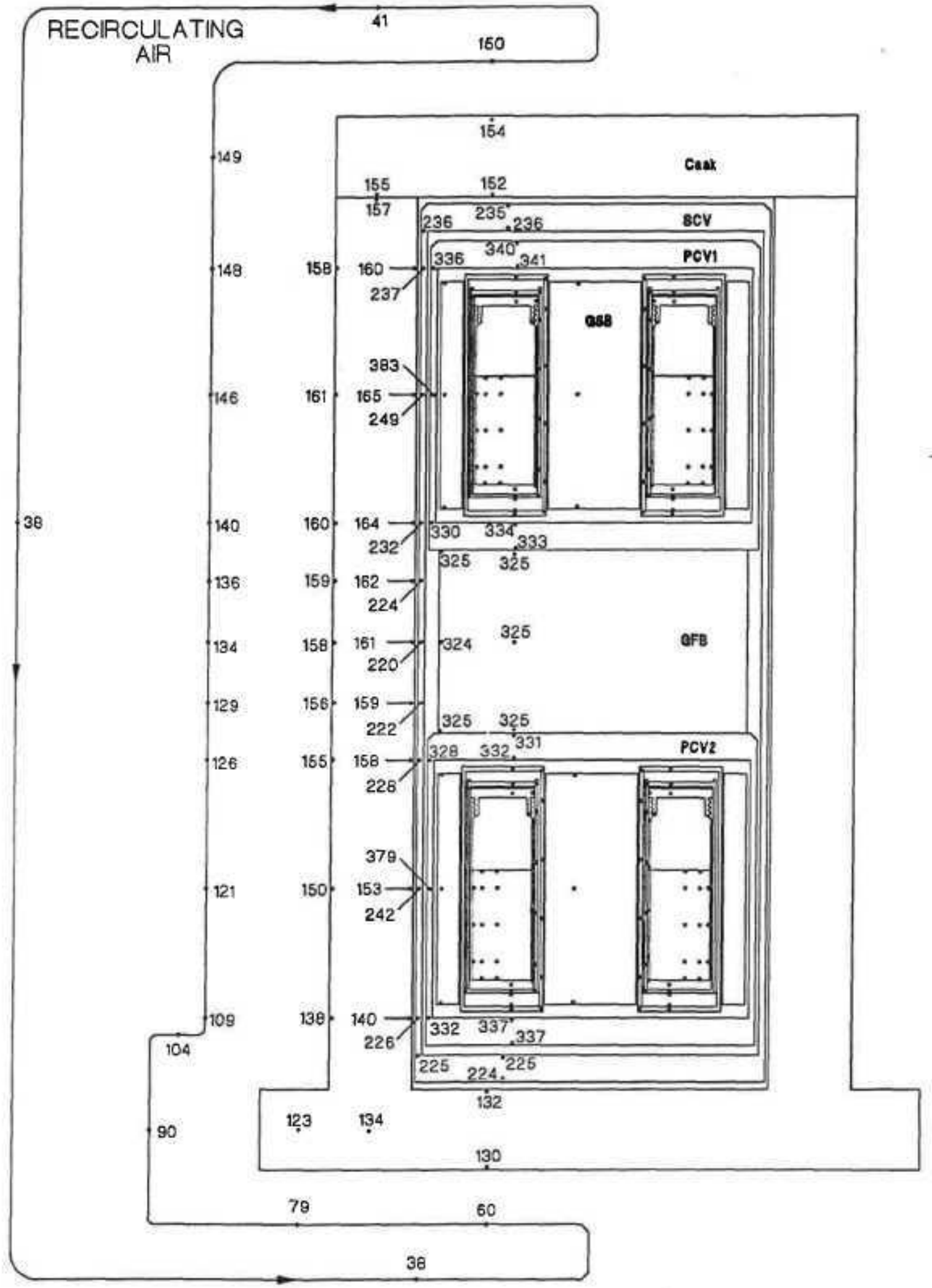

FIGURE 5. Steady State Temperatures of Middle Cask with 3 Casks in $38^{\circ} \mathrm{C}\left(100^{\circ} \mathrm{F}\right)$ Standard Cargo Container 


\section{CONCLUSIONS}

The Mound 9516 Shipping Package was originally designed for fuel loading of one killowatt. Subsequently it was downgraded to 500 watts. Even with very conservative assumptions, analytical results have shown that all the thermal requirements are exceeded with wide margins of safety.

\section{Acknowledgments}

The work described was performed by the authors as part of Fairchild Space and Defense Corporation, which became a wholly owned subsidiary of Orbitral Sciences Corporation on August 11, 1994. This work is supported by DOE/Radioisotope Power Systems Division under the supervision of Vince Cassella. The authors thank K. Yates and V. Kumar for their assistance in the prepara-tion of this paper.

\section{References}

Coleman, H. and C. Robinson (1991) Safety Analysis Report for Packaging (SARP) for the Mound I kW Package, EG\&G Mound Applied Technologies, Miamisburg, OH, April 1991.

Coleman, H. and C. Robinson (1992) Safety Analysis Report for Packaging (SARP) for the Mound $1 \mathrm{~kW}$ Package, Rev. 3, EG\&G Mound Applied Technologies, Miamisburg, OH, May 1992.

Gaski, J (1986) SINDA (System Improved Numerical Differencing Analyzer), version 1.23, from Network Analysis Associates, Fountain Valley, CA.

Gebhart, B. (1971) Heat Transfer, Second Edition, McGraw Hill Book Co., Cornell University, NY, 8: 375 .

H\&R Technical Associates, Inc. (1993) Evaluation of the Mound $1 \mathrm{~kW}$ Package, Russian Product Can Configuration, Rev. 1, Oak Ridge, TN, January 1993.

Kays, W.M. and M.E. Crawford (1980) Convective Heat and Mass Transfer, Second Edition, McGraw Hill Book Company, Stanford University, CA, 16: 318.

Little (1986) SSPTA (Simplified Space Payload Thermal Analyzer), version 3.0/VAX, for NASA/Goddard under Contract NAS5-27606 by Arthur D. Little Inc, Cambridge, MA.

Or, C. (1994) "Thermal Analysis of the Mound One Kilowatt Package," in Proc. of the Ilth Symposium on Space Nuclear Power and Propulsion, M.S. El-Genk ed., American Institute of Physics, Conf. Proc. No. 271, 1: 159-170. 